\title{
Asymmetric Transformations by Coupled Enzyme and Metal Catalysis: Dynamic Kinetic Resolution
}

Mahn-Joo Kim, Jaiwook Park, and Yoon Kyung Choi

\section{1}

\section{Introduction}

The enzymatic resolution of racemic substrates now is a well-established approach for the synthesis of single enantiomers [1, 2]. A representative example is the kinetic resolution of secondary alcohols via lipase-catalyzed transesterification for the preparation of enantiomerically enriched alcohols and esters [3]. The enzymatic resolution in general is straightforward and satisfactory in terms of optical purity, but it has an intrinsic limitation in that the theoretical maximum yield of a desirable enantiomer cannot exceed $50 \%$. Accordingly, additional processes such as isolation, racemization and recycling of unwanted isomers are required to obtain the desirable isomer in a higher yield (Scheme 1.1).

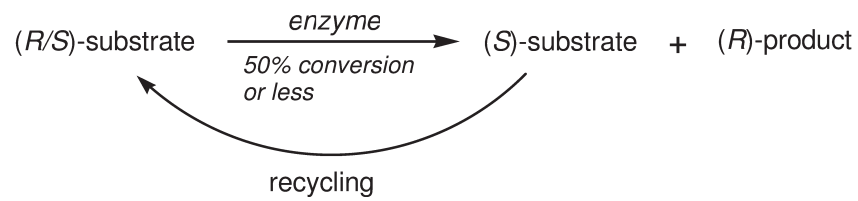

Scheme 1.1 (R)-Selective enzymatic resolution with recycling of unreacted $(S)$-substrate.

The limitation of enzymatic resolution, however, can be overcome by introducing an efficient catalyst for racemization of substrate into the resolution, leading to the process called dynamic kinetic resolution (DKR) [4]. Theoretically, DKR can provide single enantiomeric products [99\% enantiomeric excess (e.e.) or greater] in $100 \%$ yield in the case where a highly efficient racemization catalyst is combined with a highly enantioselective enzyme. In the last decade, several metal-based catalysts have been developed for the racemization and successfully incorporated into the resolution process [5]. Now a wide range of racemic substrates can be converted to enantiomeric products of high optical purity in good yields via the enzymometallic DKR (Scheme 1.2). This chapter covers these developments with detailed examples. 
(R)-substrate enzyme

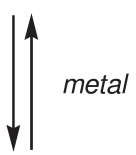

(S)-substrate

(R)-substrate

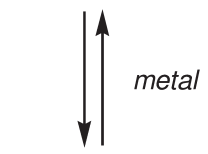

(S)-substrate

enzyme $\longrightarrow$ (S)-product

Scheme $1.2(R)$ - and $(S)$-Selective enzymo-metallic DKR.

1.2

\section{Some Fundamentals for DKR}

\subsection{1}

\section{Enzymes for Kinetic Resolution}

The resolution of a racemic substrate can be achieved with a range of hydrolases including lipases and esterases. Among them, two commercially available lipases, Candida antarctica lipase B (CALB; trade name, Novozym-435) and Pseudomonas cepacia lipase (PCL; trade name, Lipase PS-C), are particularly useful because they have broad substrate specificity and high enantioselectivity. They display satisfactory activity and good stability in organic media. In particular, CALB is highly thermostable so that it can be used at elevated temperature up to $100^{\circ} \mathrm{C}$.

The lipase-catalyzed resolutions usually are performed with racemic secondary alcohols in the presence of an acyl donor in hydrophobic organic solvents such as toluene and tert-butyl methyl ether (Scheme 1.3). In case the enzyme is highly enantioselective ( $E=200$ or greater), the resolution reaction in general is stopped at nearly $50 \%$ conversion to obtain both unreacted enantiomers and acylated enantiomers in enantiomerically enriched forms. With a moderately enantioselective enzyme $(E=20-50)$, the reaction carries to well over $50 \%$ conversion to get unreacted enantiomer of high optical purity at the cost of acylated enantiomer of lower optical purity. The enantioselectivity of lipase is largely dependent on the structure of substrate as formulated by Kazlauskas [6]: most lipases show

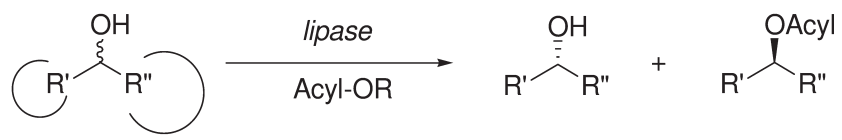

Scheme 1.3 Lipase-catalyzed resolution of secondary alcohols. 
$(R)$-selectivity toward simple secondary alcohols carrying one small and one relatively larger substituent at the hydroxyl methane center, and the selectivity in general increases with an increase in the size difference between two substituents. The size of the small substituent limits the reactivity of substrate toward lipase. If it exceeds a three-carbon unit, the substrate reacts very slowly or does not react at a synthetically useful rate. Accordingly, the Kazlauskas rule is useful as a guideline for predicting substrates that can be efficiently resolved by lipase as well as the stereochemistry of resolved substrates.

Lipase, which is highly useful for kinetic resolution, however, has a limitation for use in DKR in that it cannot be used for $(S)$-configuration products. For this purpose, subtilisin, a protease from Bacillus licheniformis, can replace lipase since it provides complementary enantioselectivity (Scheme 1.4). Subtilisin, however, has been much less frequently employed in resolution compared to lipase because it displays poor catalytic performance in organic media. Subtilisin is inferior to lipase in several properties such as activity, enantioselectivity and stability. Accordingly, the use of the enzyme usually requires some special treatments for activation and stabilization before use. For example, the treatment of subtilisin with surfactants has enhanced substantially its activity and stability up to a synthetically useful level.

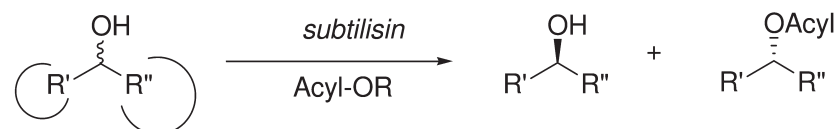

Scheme 1.4 Subtilisin-catalyzed resolution of secondary alcohols.

\subsection{2}

\section{Metal Catalysts for Racemization}

Many different metal catalysts have been explored for racemization of secondary alcohols. Among them, ruthenium-based organometallic complexes have been most intensively tested as the racemization catalyst (Figure 1.1).

These ruthenium catalysts catalyze the racemization of secondary alcohol through a dehydrogenation/hydrogenation cycle with or without releasing ketone as a byproduct (Scheme 1.5). Catalysts 6-9 display good activities at room temperature, while others show satisfactory activities at elevated temperatures. Catalyst 1 , for example, requires a high temperature $\left(70^{\circ} \mathrm{C}\right)$ for dissociation into two monomeric species (1a and $\mathbf{1 b})$ acting as racemization catalysts (Scheme 1.6).

Most ruthenium catalysts except 8 and 9 are highly sensitive to oxygen or air and must be used under anaerobic conditions. The latter can be used under aerobic conditions. Currently, no rationale is available for explaining the difference in stability between these ruthenium catalysts. In general, racemizations by these catalysts take place more rapidly with benzylic alcohols compared to non-benzylic or aliphatic alcohols. 
\begin{tabular}{l|ll}
4 & 1 Asymmetric Transformations by Coupled Enzyme and Metal Catalysis
\end{tabular}
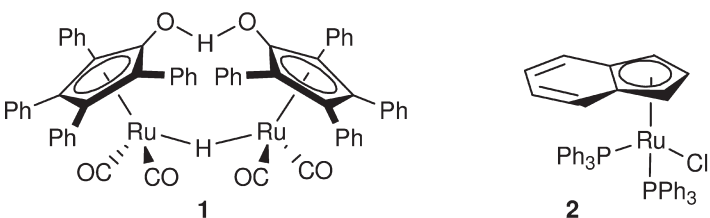<smiles>[X][R](Cl)(Br)[Bi]Br</smiles>

3a: $\mathrm{Ar}=p$-cymene, $\mathrm{X}=\mathrm{Cl}$

3b: $\mathrm{Ar}=p$-cymene, $\mathrm{X}=\mathrm{H}$

3c: $\mathrm{Ar}=$ mesityene, $\mathrm{X}=\mathrm{Cl}$

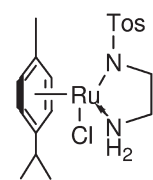

4

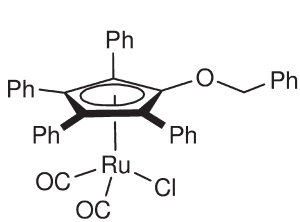

8

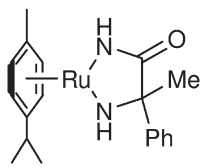

5

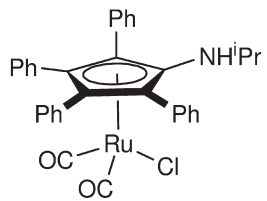

6

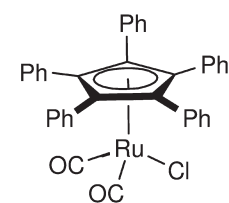

7

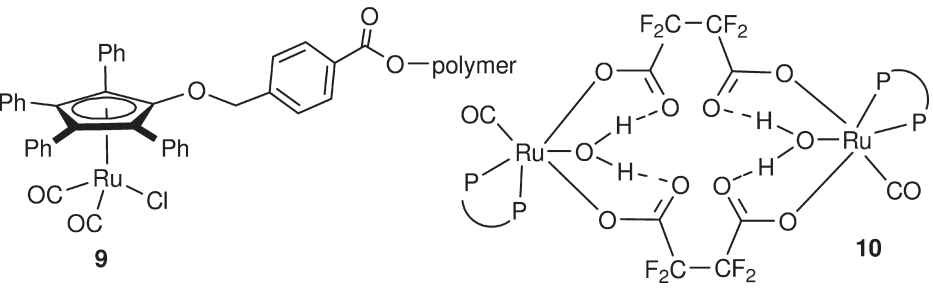

Figure 1.1 Ruthenium catalysts.

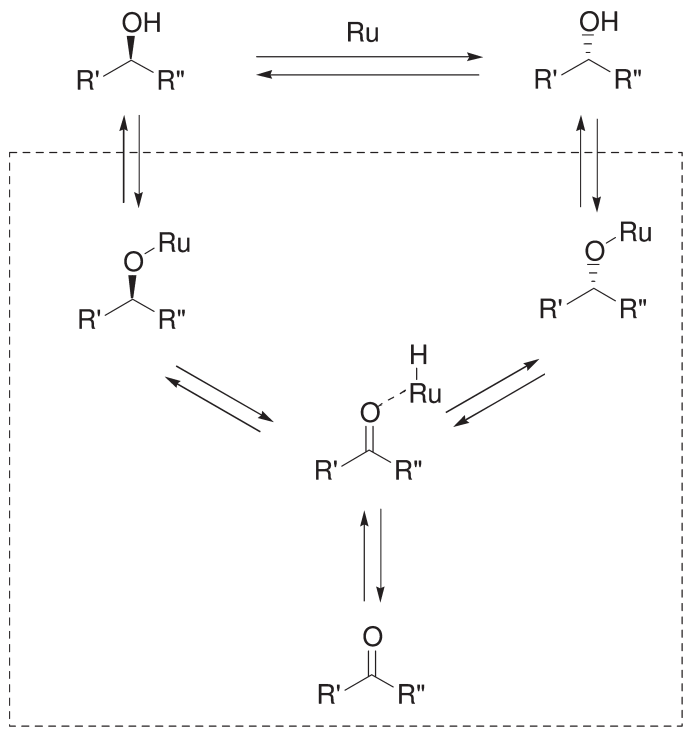

Scheme 1.5 A simplified mechanism for ruthenium-catalyzed racemization of sec-alcohol.

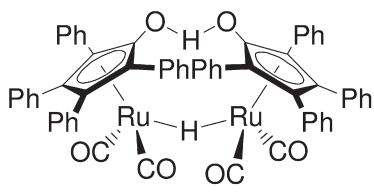

1

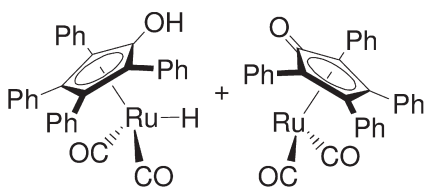

1a
$1 b$

Scheme 1.6 Dissociation of catalyst 1. 


\section{2 .3}

\section{Enzyme-Metal Combination for DKR}

DKR of secondary alcohol is achieved by coupling enzyme-catalyzed resolution with metal-catalyzed racemization. For efficient DKR, these catalytic reactions must be compatible with each other. In the case of DKR of secondary alcohol with the lipase-ruthenium combination, the use of a proper acyl donor (required for enzymatic reaction) is particularly crucial because metal catalyst can react with the acyl donor or its deacylated form. Popular vinyl acetate is incompatible with all the ruthenium complexes, while isopropenyl acetate can be used with most monomeric ruthenium complexes. $p$-Chlorophenyl acetate (PCPA) is the best acyl donor for use with dimeric ruthenium complex 1. On the other hand, reaction temperature is another crucial factor. Many enzymes lose their activities at elevated temperatures. Thus, the racemization catalyst should show good catalytic efficiency at room temperature to be combined with these enzymes. One representative example is subtilisin. This enzyme rapidly loses catalytic activities at elevated temperatures and gradually even at ambient temperature. It therefore is compatible with the racemization catalysts 6-9, showing good activities at ambient temperature. In case the racemization catalyst requires an elevated temperature, CALB is the best counterpart.

\subsection{4}

\section{$(R)$ - and (S)-Selective DKR}

Thanks to two complementary enzymes, lipase and subtilisin, both $(R)$ - and $(S)$ selective DKR can be performed to obtain the corresponding enantiomeric products.

DKR by the lipase-ruthenium combination provides $(R)$-products, while DKR by the subtilisin-ruthenium combination gives products of the opposite configuration (Schemes 1.7 and 1.8).

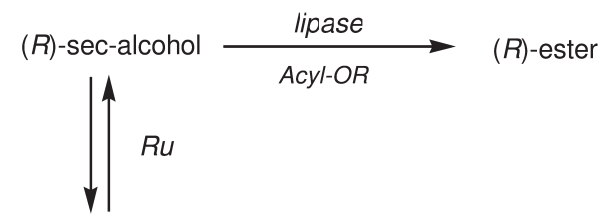

(S)-sec-alcohol

Scheme $1.7(R)$-Selective DKR with the lipase-ruthenium combination.

$(R)$-sec-alcohol

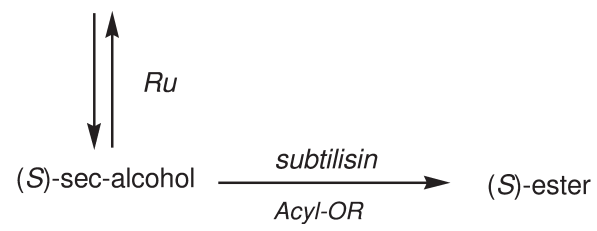

Scheme 1.8 (S)-Selective DKR with the subtilisin-ruthenium combination. 


\section{3}

\section{Examples of DKR}

\subsection{1}

\section{First DKR of Secondary Alcohols}

The first use of a metal catalyst in the DKR of secondary alcohols was reported by Williams et al. [7]. In this work, various rhodium, iridium, ruthenium and aluminum complexes were tested. Among them, only $\mathrm{Rh}_{2}(\mathrm{OAc})_{4}$ and $[\mathrm{Rh}(\mathrm{cod}) \mathrm{Cl}]_{2}$ showed reasonable activity as the racemization catalyst in the DKR of 1-phenylethanol. The racemization occurred through transfer-hydrogenation reactions and required stoichiometric amounts of ketone as hydrogen acceptor. The DKR of 1-phenylethanol performed with $\mathrm{Rh}_{2}(\mathrm{OAc})_{4}$ and Pseudomonas fluorescens lipase gave $(R)$-1-phenylethyl acetate of $98 \%$ e.e. at $60 \%$ conversion after $72 \mathrm{~h}$.

\subsection{2}

\section{DKR of Secondary Alcohols with Racemization Catalyst 1}

Significantly improved DKR was reported by Bäckvall et al. who used diruthenium complex 1 together with CALB [8]. This work demonstrated for the first time the superiority of PCPA as the acyl donor over popular acyl donors such as vinyl and isopropenyl acetate. The DKR of 1-phenylethanol by this procedure afforded optically pure (R)-1-phenylethyl acetate in a high yield (Scheme 1.9) [8b].

However, the procedure has some drawbacks to overcome. First, it requires an elevated temperature $\left(70^{\circ} \mathrm{C}\right)$ for the activation of the racemization catalyst. Such a high temperature is unacceptable for thermally less-stable enzymes. Second, the racemization proceeds through a mechanism including the release of ketone as a byproduct and thus the lowering of yield is inevitable. Third, PCPA used in an

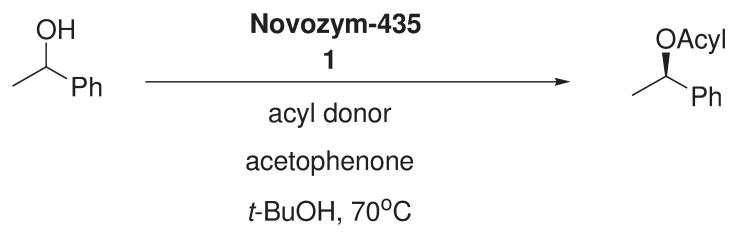

\begin{tabular}{ccc}
\hline acyl donor & ee $(\%)$ & yield $(\%)$ \\
\hline vinyl acetate & $>99$ & 50 \\
Isopropenyl acetate & $>99$ & 72 \\
p-chlorophenyl acetate & $>99$ & 100 \\
\hline
\end{tabular}

Scheme 1.9 DKR of 1-phenylethanol with ruthenium catalyst 1. 


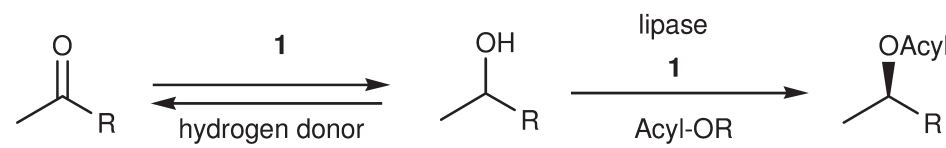

Scheme 1.10 Hydrogenation and DKR of ketones.

excess amount is often difficult to remove from the acylated products during workup. In spite of these limitations, the procedure with ruthenium catalyst $\mathbf{1}$ has been successfully applied in the DKR of a variety of simple and functionalized alcohols, including diols [9], hydroxy acid esters [9b, 10], hydroxyl aldehydes [9b], $\beta$-azido alcohols [11], $\beta$-hydroxyl nitriles [12], $\beta$-halo alcohols [13] and hydroxyalkanephosphonates [14].

An interesting application of $\mathbf{1}$ is the use in the asymmetric reductive acetylation of ketones via DKR of alcohol intermediates. In this transformation, rutheniumcatalyzed hydrogenation of ketone takes place in a concerted fashion with DKR of alcohol to produce the corresponding acyl products (Scheme 1.10). The idea of this process was to take advantage of ketone formation, which is a problem observed in the DKR of secondary alcohols with 1 . A key to this process was the selection of hydrogen donors compatible with the DKR conditions. 2,6-Dimethyl-4-heptanol, which cannot be acylated by lipases, and hydrogen molecules were effective hydrogen donors [15]. Asymmetric reductive acetylation of ketones under $1 \mathrm{~atm}$ hydrogen in ethyl acetate gave products in good yields and high optical purities (Scheme 1.11) [15b]. Here, ethyl acetate was used as both acyl donor and solvent.

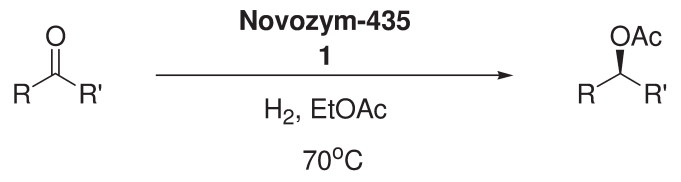

\begin{tabular}{cccc}
\hline $\mathrm{R}$ & $\mathrm{R}^{\prime}$ & ee $(\%)$ & yield (\%) \\
\hline $\mathrm{Me}$ & $\mathrm{Ph}$ & 96 & 81 \\
$\mathrm{Me}$ & $4-\mathrm{MeO}-\mathrm{Ph}$ & 99 & 85 \\
$\mathrm{Me}$ & $4-\mathrm{Cl}-\mathrm{Ph}$ & 97 & 72 \\
\hline
\end{tabular}

Scheme 1.11 Asymmetric reductive acetylation of ketones.

Asymmetric reductive acetylation was also applicable to acetoxyphenyl ketones. In this case the substrate itself acts as an acyl donor. For example, $m$-acetoxyacetophenone was transformed to ( $R$ )-1-(3-hydroxyphenyl)ethyl acetate under $1 \mathrm{~atm}$ $\mathrm{H}_{2}$ in $95 \%$ yield [16] (Scheme 1.12). The pathway of this reaction is rather complex. It was confirmed that nine catalytic steps are involved: two steps for rutheniumcatalyzed reductions, two steps for ruthenium-catalyzed racemizations, two steps 


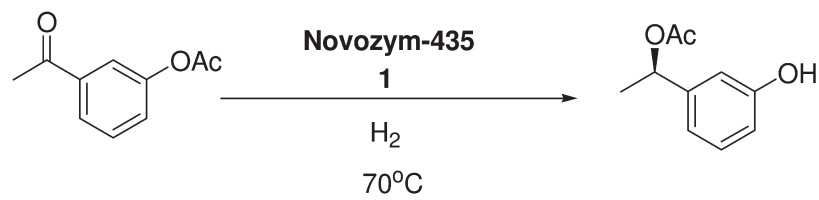

Scheme 1.12 Asymmetric transformation of $m$-acetoxyacetophenone.

for ruthenium-catalyzed deacylations and three steps for lipase-catalyzed acylations. This process was applicable to a wide range of acyloxyphenyl ketones.

Another example showing the utility of $\mathbf{1}$ is the asymmetric hydrogenation of vinyl esters which usually are used as acyl donors in enzymatic resolution. In this transformation, vinyl esters are converted to ketones which then undergo asymmetric reductive acylation to give chiral esters as described in Scheme 1.13. The overall reaction thus corresponds to the asymmetric hydrogenation of vinyl ester to the corresponding alkyl esters.<smiles>CC(=O)OC(C)=CP</smiles><smiles>[R][C@H](C[PH])C(C)=O</smiles>

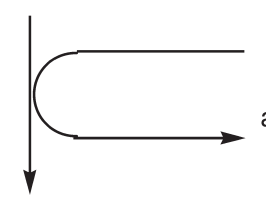

lipase acetylated lipase<smiles>[R]CC([R])=O</smiles>

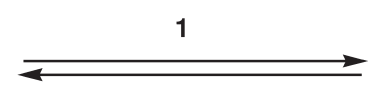

$\mathrm{H}_{2}$ or

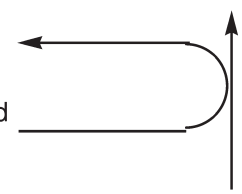

2,6-dimethyl-4-heptanol

Scheme 1.13 Asymmetric hydrogenation of vinyl esters.

The reaction was carried out with CALB and diruthenium complex 1 in the presence of 2,6-dimethyl-4-heptanol or molecular hydrogen (1 atm). In the case of 1-phenylvinyl acetate, $(R)$-1-phenylethyl acetate was obtained in $89 \%$ yield and $98 \%$ ee (Scheme 1.14) [15a].

\section{3 .3}

\section{DKR of Secondary Alcohols with Racemization Catalyst 2}

We reported the use of an indenyl ruthenium complex 2 as a racemization catalyst which did not produce ketones as the byproducts [17]. The metal catalyst requires a weak base like triethylamine and molecular oxygen to be activated. The DKR with 2 in combination with an immobilized PCL was carried out at a lower temperature $\left(60^{\circ} \mathrm{C}\right)$ to afford good yields and high optical purities (Scheme 1.15). It is noteworthy that 2 does not require ketone as hydrogen mediator for racemization. 


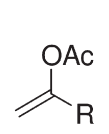

Novozym-435

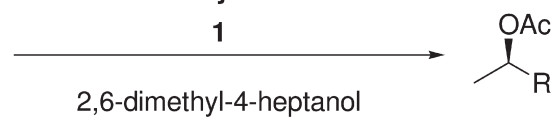

\begin{tabular}{ccc|ccc}
\hline $\mathrm{R}$ & ee (\%) & yield (\%) & $\mathrm{R}$ & ee (\%) & yield (\%) \\
\hline $\mathrm{Ph}$ & 98 & 89 & $\mathrm{PhCH}_{2}$ & 79 & 90 \\
4-MeO-Ph & 98 & 80 & $\mathrm{PhCH}_{2} \mathrm{CH}_{2}$ & 94 & 92 \\
4-Cl-Ph & 97 & 91 & $\mathrm{CH}_{3}\left(\mathrm{CH}_{2}\right)_{4} \mathrm{CH}_{2}$ & 91 & 95 \\
$c-\mathrm{C}_{6} \mathrm{H}_{11}$ & 99 & 94 & & & \\
\hline
\end{tabular}

Scheme 1.14 Asymmetric hydrogenation of vinyl acetates.

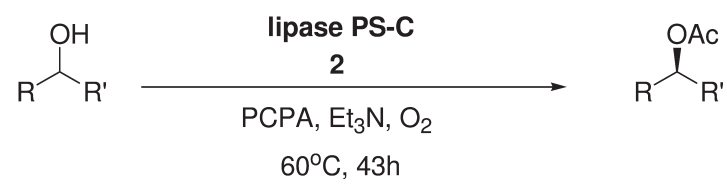

\begin{tabular}{cccc}
\hline $\mathrm{R}$ & $\mathrm{R}^{\prime}$ & ee $(\%)$ & yield (\%) \\
\hline $\mathrm{Me}$ & $\mathrm{Ph}$ & 96 & 86 \\
$\mathrm{Me}$ & $\mathrm{Ph}-4-\mathrm{OMe}$ & 99 & 82 \\
$\mathrm{Me}$ & $\mathrm{Ph}-4-\mathrm{Br}$ & 99 & 98 \\
$\mathrm{Me}$ & $\mathrm{CH}_{2} \mathrm{Ph}$ & 97 & 60 \\
\hline
\end{tabular}

Scheme 1.15 DKR with indenyl ruthenium complex 2.

This work thus presented the first example for DKR without the formation of ketones as the side products.

\subsection{4}

\section{DKR of Secondary Alcohols with Racemization Catalyst 3}

We discovered that cymene-ruthenium catalysts $3 a-c$ were effective catalyst systems for facile DKR of secondary alcohols at $40^{\circ} \mathrm{C}$. This catalyst system was particularly useful for the DKR of allylic alcohols [18], which underwent smoothly at room temperature to provide the corresponding chiral acetates with excellent optical purities (Scheme 1.16). This work has for the first time demonstrated that DKR can be performed at room temperature.

Interestingly, catalyst 3a showed higher racemization activities in ionic liquids such as $\left[\mathrm{EMIm}_{3} \mathrm{BF}_{4}\right.$ and $\left[\mathrm{BMIm} \mathrm{PF}_{6}\right.$ ([EMIm]=1-ethyl-3-methylimidazolium, $[$ BMIm] $=1$-butyl-3-methyl-imidazolium) [19]. The DKR in ionic liquids has one big 
<smiles>CC(O)C=CP</smiles>

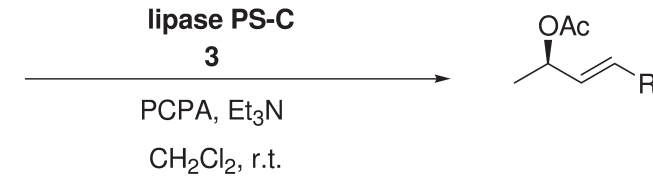

\begin{tabular}{ccc}
\hline $\mathrm{R}$ & ee (\%) & yield (\%) \\
\hline $\mathrm{Ph}$ & $>99$ & 84 \\
4-Cl-Ph & 99 & 91 \\
4-MeO-Ph & 99 & 85 \\
2-furyl & 99 & 92 \\
$\mathrm{c}-\mathrm{C}_{6} \mathrm{H}_{11}$ & 95 & 90 \\
$\left(\mathrm{CH}_{3}\right)_{3} \mathrm{C}$ & $>99$ & 85
\end{tabular}

Scheme 1.16 DKR of allylic alcohols with cymene-ruthenium catalyst 3.

advantage that both ruthenium catalyst and enzyme together with ionic liquid can be reused after a simple extraction of the products by ether [20].

1.3.5

\section{DKR of Secondary Alcohols with Racemization Catalyst 4}

Chiral $\mathrm{Ru}(\mathrm{II})$ complexes formed from $\left[\mathrm{RuCl}_{2}(p \text {-cymene) }]_{2}\right.$ and chiral bidentate nitrogen ligands have been extensively studied as catalysts for the asymmetric transfer hydrogenation of prochiral ketones [21]. Sheldon et al. utilized an achiral analog 4 for alcohol racemization. A cocatalyst system of 4 and 2,2,6,6-tetramethyl1-piperidinyloxyl (TEMPO) racemized benzylic alcohols under the conditions for enzymatic acylation [22]. They suggested that a ruthenium hydride species generated from the mixture of 4, TEMPO and a benzylic alcohol is the active catalyst for racemization. This DKR process with 4 gave $(R)$-1-phenylethyl acetate (greater than $99 \%$ e.e.) in $76 \%$ yield after $48 \mathrm{~h}$ with the production of acetophenone in $15 \%$.

\subsection{6}

\section{DKR of Secondary Alcohols with Racemization Catalyst 5}

Palmans et al. prepared 5 by the reaction of $\left[\mathrm{RuCl}_{2} \text { (p-cymene) }\right]_{2}$ and 2-phenyl-2aminopropionamide in the presence of potassium carbonate. They used 5 in an iterative tandem catalysis for the synthesis of chiral oligoesters. The enzymatic ring opening of 6-methyl- $\varepsilon$-caprolactone was combined with ruthenium-catalyzed alcohol racemization to produce optically active oligomers of 6-methyl- $\varepsilon$-caprolactone [23] (Scheme 1.17).

The same catalyst system was applied to the condensation of racemic $\alpha, \alpha^{\prime}$ dimethyl-1,4-benzenedimethanol and dimethyl adipate. Optically active polyesters $\left(M_{\mathrm{w}}=3400 \mathrm{~g} / \mathrm{mol} ; M_{\mathrm{n}}=2100 \mathrm{~g} / \mathrm{mol}\right)$ were obtained [24] (Scheme 1.18). 


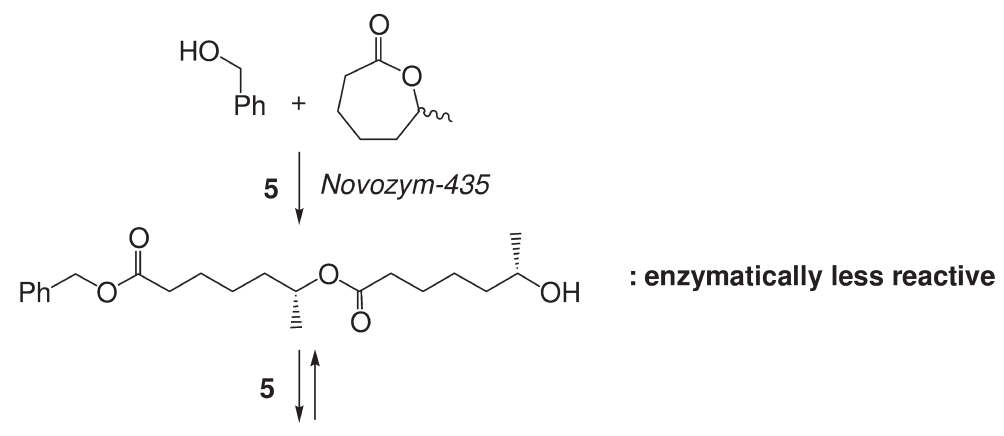<smiles>C[C@H](O)CCCCC(=O)O[C@H](C)CCCCC(=O)O[C@H](C)CCCCC(=O)O[C@H](C)CCCCC(=O)OCc1ccccc1</smiles>

Scheme 1.17 Synthesis of optically active oligoesters by DKR.<smiles>COC(=O)CCCCC(=O)OC</smiles>
Novozym-435 $\downarrow$

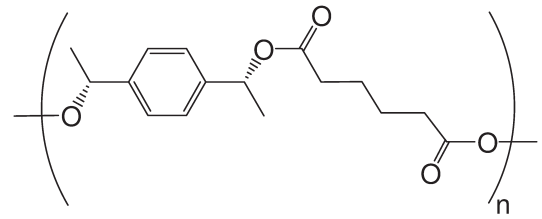

Scheme 1.18 Synthesis of optically active polyester by DKR.

\subsection{7}

\section{DKR of Secondary Alcohols with Racemization Catalyst 6}

In an effort directed at developing a racemization catalyst that works uniformly for a wide range of substrates at room temperature, we designed and synthesized a novel aminocyclopentadienyl ruthenium chloride complex 6 [25]. The DKR of 
aromatic as well as aliphatic alcohols with $\mathbf{6}$ was successfully conducted at room temperature. The resulting acylated products were obtained in high yields and in high enantiomeric excess (Scheme 1.19). In the case of aromatic alcohols the substituent effects were found insignificant in the DKR; however, comparatively aromatic alcohols have faster conversion rates than their aliphatic counterparts. These results represent the first successful DKR of secondary alcohols at room temperature.
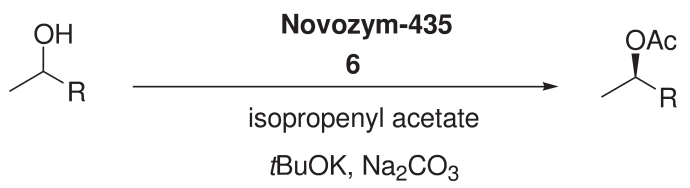

toluene, $25^{\circ} \mathrm{C}$

\begin{tabular}{ccc|ccc}
\hline $\mathrm{R}$ & ee (\%) & yield (\%) & $\mathrm{R}$ & ee (\%) & yield (\%) \\
\hline $\mathrm{Ph}$ & $>99$ & 95 & $c-\mathrm{C}_{6} \mathrm{H}_{11}$ & $>99$ & 86 \\
$\mathrm{Ph}-4-\mathrm{Cl}$ & $>99$ & 94 & $\mathrm{CH}_{2}\left(\mathrm{CH}_{2}\right)_{4} \mathrm{CH}_{3}$ & 91 & 89 \\
$\mathrm{Ph}-4-\mathrm{OMe}$ & $>99$ & 90 & $\mathrm{CH}_{2} \mathrm{O}(\mathrm{Ph})_{3} \mathrm{C}$ & 99 & 97 \\
$\mathrm{Ph}-4-\mathrm{NO}_{2}$ & $>99$ & 97 & $\mathrm{CH}=\mathrm{CHPh}$ & 98 & 93 \\
$\mathrm{Ph}-4-\mathrm{CN}$ & $>99$ & 95 & & & \\
\hline
\end{tabular}

Scheme 1.19 DKR with aminocyclopentadienyl ruthenium complex 6.

An additional feature of this DKR is the use of isopropenyl acetate, which is readily available, more active than PCPA and easily separable from the DKR mixtures [26]. Although the mechanism of the catalytic racemization is not clear yet, according to our interpretation, it can be deduced that the amino group in $\mathbf{6}$ seems to play a crucial role in the racemization.

The high activity of $\mathbf{6}$ at room temperature allowed us for the first time to combine it with thermally weak subtilisin for the $(S)$-selective DKR. A commercially available form of subtilisin is not practical due to its low activity and instability. However, we succeeded in enhancing its activity and stability by treating it with a surfactant before use. Room temperature DKRs with subtilisin and ruthenium catalyst $\mathbf{6}$ were performed in the presence of trifluoroethyl butanoate as an acylating agent, and the $(S)$-products were obtained in good yields and high optical purities (Scheme 1.20) [27].

\subsection{8}

\section{DKR of Secondary Alcohols with Racemization Catalyst 7}

Bäckvall et al. found that 7 also catalyzes efficiently the racemization of alcohols at room temperature after being activated by potassium tert-butoxide [28a]. The racemization of 1 -phenylethanol was completed within $10 \mathrm{~min}$ by using $0.5 \mathrm{~mol} \%$ 


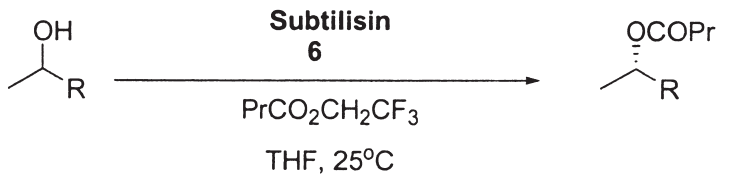

\begin{tabular}{ccc|ccc}
\hline $\mathrm{R}$ & ee (\%) & yield (\%) & $\mathrm{R}$ & ee (\%) & yield (\%) \\
\hline $\mathrm{Ph}$ & 92 & 95 & $\mathrm{CH}_{2} \mathrm{Ph}$ & 92 & 77 \\
$\mathrm{Ph}-4-\mathrm{Cl}$ & 99 & 92 & $\mathrm{CH}_{2} \mathrm{CH}_{2} \mathrm{Ph}$ & 98 & 80 \\
$\mathrm{Ph}-4-\mathrm{MeO}$ & 94 & 93 & $\mathrm{CH}_{2}\left(\mathrm{CH}_{2}\right)_{4} \mathrm{CH}_{3}$ & 98 & 77 \\
${ }^{-}-\mathrm{C}_{6} \mathrm{H}_{11}$ & 98 & 80 & $\mathrm{CH}=\mathrm{CHPh}$ & 95 & 90 \\
\hline
\end{tabular}

Scheme $1.20(S)$-Selective DKR by the subtilisin-ruthenium combination.

of 7 at room temperature. They succeeded in alcohol DKR by using 7, CALB and isopropenyl acetate as acyl donor at room temperature [28b, 28c]. Under optimized conditions the DKR of benzylic alcohols was about one order of magnitude faster than the previous DKR with 6. For example, the DKR of 1-phenylethanol was completed in $3 \mathrm{~h}$ (Scheme 1.21). This catalyst system was also effective for the DKR of aliphatic alcohols. The synthesis of (S)-esters was performed by combining 7 and surfactant-treated subtilisin [29].

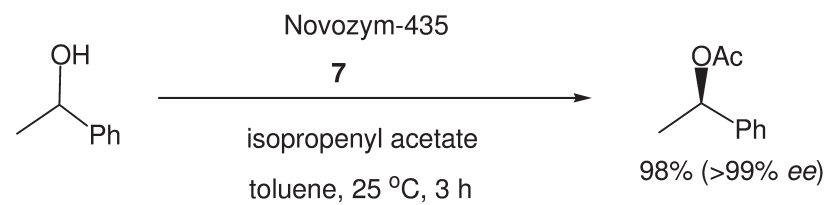

Scheme 1.21 DKR with racemization catalyst 7 .

\subsection{9}

DKR of Secondary Alcohols with Air-Stable Racemization Catalysts

We synthesized 8 by the one-step reaction of $\left[\mathrm{Ph}_{4}\left(\eta^{4}-\mathrm{C}_{4} \mathrm{CO}\right)\right] \mathrm{Ru}(\mathrm{CO})_{3}$ with benzyl chloride. In contrast to previous alcohol racemization catalysts, 8 was stable in the air during racemization [30]. The racemization was performed even under $1 \mathrm{~atm}$ of molecular oxygen. Thus, alcohol DKR was for the first time possible with 8 in the air at room temperature; $(R)$-1-phenylethyl acetate $(99 \%$ yield, greater than $99 \%$ e.e.) was obtained from 1-phenylethanol by using 4 mol\% of 8 , CALB and isopropenyl acetate in the presence of potassium phosphate (Scheme 1.22). This catalyst system was effective for both benzylic and aliphatic alcohols. The synthetic method for 8 was applied to the preparation of a polymer-bound derivative (9). Hydroxymethyl polystyrene was reacted with 4-(chloromethyl)benzoyl chloride to 

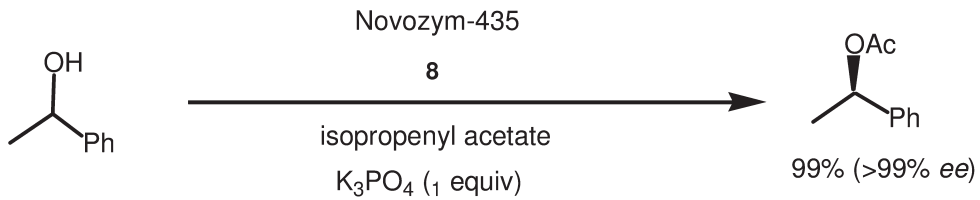

toluene, $25{ }^{\circ} \mathrm{C}, 20 \mathrm{~h}$

Scheme 1.22 DKR with racemization catalyst 8.

attach chlorobenzyl groups. Heating a mixture of the resulting polymer and $\left[\mathrm{Ph}_{4}\left(\eta^{4}-\mathrm{C}_{4} \mathrm{CO}\right)\right] \mathrm{Ru}(\mathrm{CO})_{3}$ gave the polymer 9 , which are readily recyclable for practical DKR.

\subsubsection{0}

\section{DKR of Secondary Alcohols with Racemization Catalyst 10}

Hulshof et al. introduced 10 as an alcohol racemization catalyst [31]. Alcohol DKR was performed with $0.1 \mathrm{~mol} \%$ of 10 , CALB, isopropyl butyrate as the acyl donor, potassium carbonate and about $20 \mathrm{~mol} \%$ of the corresponding ketone at $70^{\circ} \mathrm{C}$ (Scheme 1.23). Without the ketone, yield and optical purity of the product ester were decreased significantly. 2-Propanol produced by the acyl transfer reaction was removed at reduced pressure during the DKR to shift the equilibrium to acylated products.

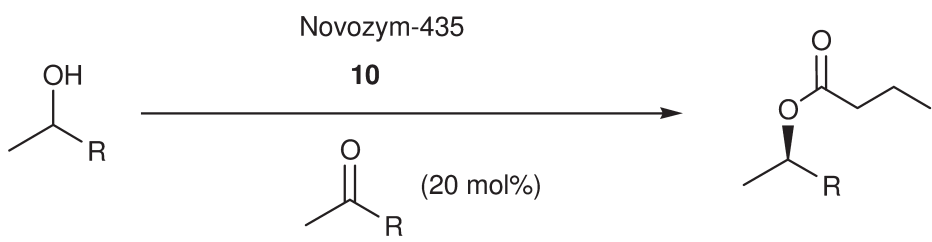

isopropyl butyrate, $\mathrm{K}_{3} \mathrm{CO}_{3}$. toluene

200 mbar Ar, 10 30 h. $70^{\circ} \mathrm{C}$

Scheme 1.23 DKR with racemization catalyst 10 .

\subsubsection{1}

\section{DKR of Secondary Alcohols with Aluminum Catalysts}

Based on the catalytic activity of aluminum alkoxides in the Meerwein-PonndorfVerley-Oppenauer reaction, Berkessel et al. envisioned that aluminum complexes can act as alcohol racemization catalysts [32]. Aluminum alkoxide complexes generated from a 1:1 mixture of $\mathrm{AlMe}_{3}$ and a bidentate ligand such as binol or 2,2'biphenol were effective catalysts for alcohol racemization. At room temperature, $10 \mathrm{~mol} \%$ of the aluminum catalyst racemized 1-phenylethanol completely within $3 \mathrm{~h}$ in the presence of 0.5 equiv. of acetophenone. The aluminum catalysts were 
applicable for the DKR of various alcohols. However, a specific acylating reagent was required for each of the resolved alcohols. The enol ester derived from ketone corresponding to each alcohol substrate must be employed as the specific acyl donor. For example, (R)-1-phenylethyl acetate (96\% e.e.) was obtained in 96\% yield from a mixture of 1-phenylethanol and 1-phenylvinyl acetate (1.2 equiv.) by using $\mathrm{AlMe}_{3}(10 \mathrm{~mol} \%)$, binol $(10 \mathrm{~mol} \%)$ and CALB at room temperature (Scheme 1.24).

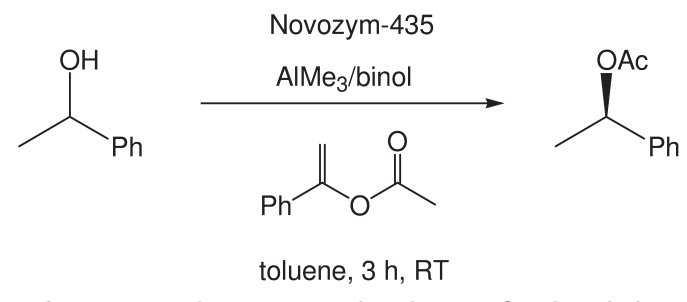

Scheme 1.24 Aluminum-catalyzed DKR of 1-phenylethanol.

\subsubsection{2}

\section{DKR of Secondary Alcohols with Vanadium Catalysts}

Oxovanadium $(\mathrm{V})$ complex, $\mathrm{VO}(\mathrm{OR})_{3}$, has been known to catalyze the rearrangement of allylic alcohols through the formation of allyl vanadate intermediates [33] (Scheme 1.25). Akai et al. employed vanadium complexes for the DKR of allyic alcohols. They selected $\mathrm{VO}\left(\mathrm{OSiPh}_{3}\right)_{3}$ and optimized conditions for the DKR of 1-cyclohexylidenepropan-2-ol. (R)-1-Cyclohexylidenepropan-2-yl acetate (98\% ee) was obtained in $95 \%$ yield by using $10 \mathrm{~mol} \%$ of $\mathrm{VO}\left(\mathrm{OSiPh}_{3}\right)_{3}$, ethoxyvinyl acetate as acyl donor and CALB in acetone at room temperature for $60 \mathrm{~h} \mathrm{[34]}$ (Scheme 1.26). (E)-1-(Prop-1-enyl)cyclohexanol was formed as the byproduct at 5\%.

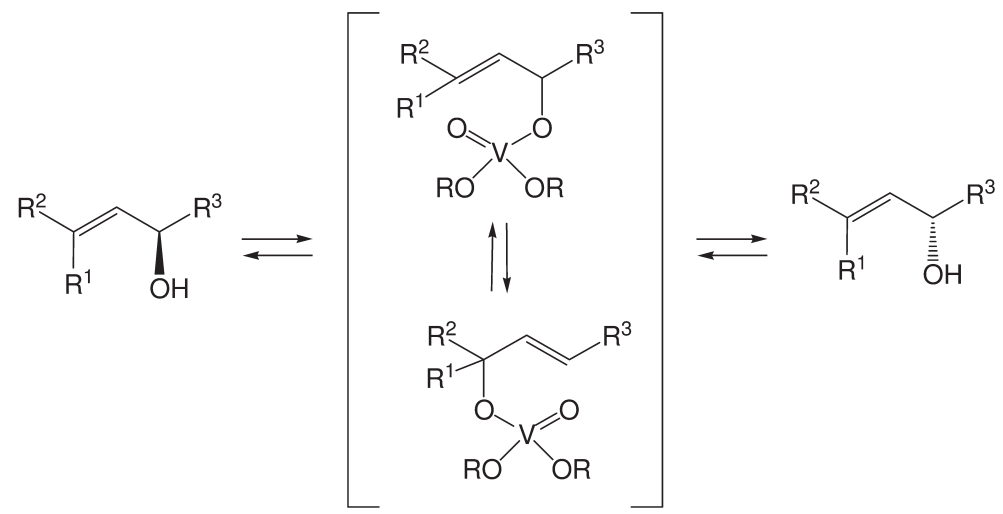

Scheme 1.25 Vanadium-catalyzed racemization of allylic alcohol. 


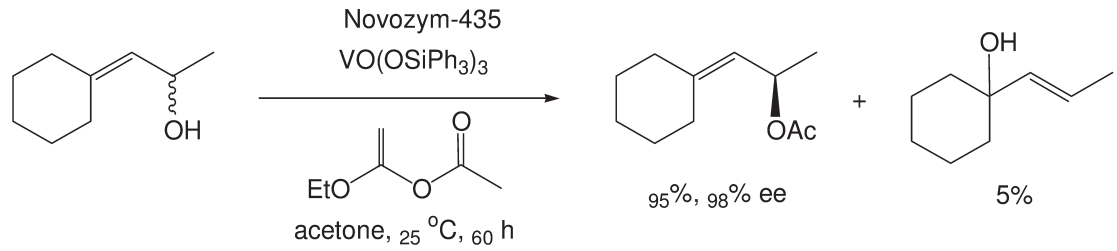

Scheme 1.26 DKR of allylic alcohols with $\mathrm{VO}\left(\mathrm{OSiPH}_{3}\right)_{3}$.

The amount of the byproduct could be minimized to near $0 \%$ if more efficient racemization can be achieved.

\section{4}

\section{Conclusions}

We have demonstrated that enzyme-metal combinations are of great use as a new class of catalyst systems for the conversion of racemic substrates to single enantiomeric products. A wide range of substrates were converted into their respective enantiopure products under DKR conditions. Two enzyme-metal combination systems, lipase-ruthenium and subtilisin-ruthenium, are particularly useful for the DKR of sec-alcohols. They are complementary in stereoselectivity. The former provides $(R)$-products, while the latter gives $(S)$-products. These catalyst systems are readily available or can be prepared without difficulty. The DKR reactions with them can be performed at ambient temperatures, and provide high yields and excellent optical purities in many cases. However, the scope of DKR is limited by the specificity of catalysts, both enzyme and metal. Accordingly, new catalysts should be developed to expand the range of substrates resolved through DKR. These catalysts should be highly active and thermally stable. In the near future, we could see the developments of many different types of enzyme-metal combinations that are applicable for the DKR of substrates other than sec-alcohols (Scheme 1.27). Currently, several groups are developing efficient metal catalysts applicable for the DKR of amines and amino acids [35]. We also could see the development of recyclable enzyme-metal catalysts so that DKR can become practically good enough to use in the industrial manufacturing of enantiopure chiral compounds.

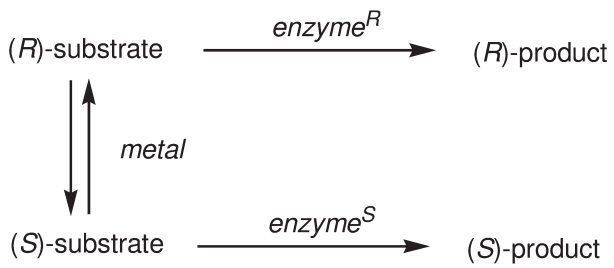

Scheme 1.27 Generalized enzymo-metallic DKR. 


\section{References}

1 Sheldon, R.A. (1993) Chirotechnology, Industrial Synthesis of Optically Active Compounds, Dekker, New York.

2 (a) Wong, C.-H. and Whitesides, G.M. (1994) Enzymes in Synthetic Organic Chemistry, Pergamon, Oxford.

(b) Koskinen, A.M.P. and Klibanov, A.M. (1996) Enzymatic Reactions in Organic Media, Blackie Academic \& Professional, Glasgow.

(c) Faber, K. (1997) Biotransformations in Organic Chemistry, 3rd edn, Springer, Berlin.

(d) Bornscheuer, U.T. and Kazlauskas, R.J. (1999) Hydrolases in Organic Synthesis, Wiley-VCH, Weinheim.

(e) Deauz, K. and Waldmann, H. (2002) Enzyme Catalysis in Organic Synthesis: A Comprehensive Handbook, 2nd edn, Vols I-III. Wiley-VCH, Weinheim.

3 (a) Kim, M.-J., Choi, G.-B. and Kim, H.-J. (1995) Tetrahedron Letters, 36, 6253.

(b) Kim, M.-J. and Lim, I.-T. (1996) Synlett, 2, 138.

(c) Kim, M.-J., Lim, I.-T., Choi, G.-B., Whang, S.-Y., Ku, B.-C. and Choi, J.-Y. (1996) Bioorganic and Medicinal Chemistry Letters, 6, 71.

(d) Kim, M.-J., Lim, I.-T., Kim, H.-J. and Wong, C.-H. (1997) Tetrahedron: Asymmetry, 8, 1507.

(e) Lee, D. and Kim, M.-J. (1998)

Tetrahedron Letters, 39, 2163.

(f) Chung, S.K., Chang, Y.-T., Lee, E.J., Shin, B.-G., Kwon, Y.-U., Kim, K.-C., Lee, D. and Kim, M.-J. (1998) Bioorganic and Medicinal Chemistry Letters, 8, 1503.

(g) Lee, D. and Kim, M.-J. (1999)

Tetrahedron Letters, 39, 9039.

(h) Lee, D. and Kim, M.-J. (1999) Organic Letters, 1, 925.

(i) Im, A.S., Cheong, C.S. and Lee, S.H. (2003) Bulletin of the Korean Chemical Society, 24, 1269.

(j) Kang, H.-Y., Ji, Y., Yu, Y.-K., Yu, J.-Y., Lee, Y. and Lee, S.-J. (2003) Bulletin of the Korean Chemical Society, 24, 1819.

4 Ward, R.S. (1995) Tetrahedron: Asymmetry, 6, 1475.
5 (a) Stürmer, R. (1997) Angewandte Chemie (International Edition in English), 36, 1173. (b) Azerad, R. and Buisson, D. (2000) Current Opinion in Biotechnology, 11, 565.

(c) Huerta, F.F., Minidis, A.B.E. and Bäckvall, J.-E. (2001) Chemical Society Reviews, 30, 321.

(d) Kim, M.-J., Ahn, Y. and Park, J. (2002) Current Opinion in Biotechnology, 13, 578. (e) Pellissier, H. (2004) Tetrahedron, 59, 8291.

(f) Pámies, O. and Bäckvall, J.-E. (2003) Chemical Society Reviews, 103, 3247.

(g) Pámies, O. and Bäckvall, J.-E. (2003) Current Opinion in Biotechnology, 14, 407.

(h) Turner, N.J. (2004) Current Opinion in Biotechnology, 8, 114.

6 (a) Kazlauskas, R.J., Weissfloch, A.N.E., Rappaport, A.T. and Cuccia, L.A. (1991) Journal of Organic Chemistry, 56, 2656. (b) Kazlauskas, R.J. and Weissfloch, A.N.E. (1997) Journal of Molecular Catalysis B: Enzymatic, 3, 65.

7 Dinh, P.M., Howarth, J.A., Hudnott, A.R., Williams, J.M.J. and Harries, W. (1996) Tetrahedron Letters, 37, 7623.

8 (a) Larsson, A.L.E., Persson, B.A. and Bäckvall, J.-E. (1997) Angewandte Chemie (International Edition in English), 36, 1211. (b) Persson, B.A., Larsson, A.L.E., Ray, M. L. and Bäckvall, J.-E. (1999) Journal of the American Chemical Society, 121, 1645.

(c) Lee, H.K. and Ahn, Y. (2004) Bulletin of the Korean Chemical Society, 25, 1471.

9 (a) Persson, B.A., Huerta, F.F. and Bäckvall, J.-E. (1999) Journal of Organic Chemistry, 64, 5237.

(b) Kim, M.-J., Choi, Y.K., Choi, M.Y., Kim, M.J. and Park, J. (2001) Journal of Organic Chemistry, 66, 4736.

(c) Edin, M. and Bäckvall, J.-E. (2003) Journal of Organic Chemistry, 68, 2216. (d) Martin-Matute, B. and Bäckvall, J.-E. (2004) Journal of Organic Chemistry, 69, 9191.

(e) Fransson, A.-B.L., Xu, Y., Leijondahl, K. and Bäckvall, J.-E. (2006) Journal of Organic Chemistry, 71, 6309.

10 (a) Huerta, F.F., Laxmi, S.Y.R. and Bäckvall, J.-E. (2000) Organic Letters, 2, 1037. 
(b) Huerta, F.F. and Bäckvall, J.-E. (2001) Organic Letters, 3, 1209.

(c) Runmo, A.B.L., Pámies, O., Faber, K. and Bäckvall, J.-E. (2002) Tetrahedron Letters, 43, 2983.

(d) Pámies, O. and Bäckvall, J.-E. (2002) Journal of Organic Chemistry, 67, 1261.

11 Pámies, O. and Bäckvall, J.-E. (2001) Journal of Organic Chemistry, 66, 4022.

12 Pámies, O. and Bäckvall, J.-E. (2001) Advanced Synthesis and Catalysis, 343, 726.

13 Pámies, O. and Bäckvall, J.-E. (2002) Journal of Organic Chemistry, 67, 9006.

14 Pámies, O. and Bäckvall, J.-E. (2003) Journal of Organic Chemistry, 68, 4815.

15 (a) Jung, H.M., Koh, J.H., Kim, M.-J. and Park, J. (2000) Organic Letters, 2, 409. (b) Jung, H.M., Koh, J.H., Kim, M.-J. and Park, J. (2000) Organic Letters, 2, 2487.

16 Kim, M.-J., Choi, M.Y., Han, M.Y., Choi, Y.K., Lee, J.K. and Park, J. (2002) Journal of Organic Chemistry, 67, 9481.

17 Koh, J.H., Jeong, H.M., Kim, M.-J. and Park, J. (1999) Tetrahedron Letters, 40, 6281.

18 Lee, D., Huh, E.A., Kim, M.-J., Jung, H.M., Koh, J.H. and Park, J. (2000) Organic Letters, 2, 2377.

19 (a) Kim, K.W., Song, B., Choi, M.Y. and Kim, M.-J. (2001) Organic Letters, 3, 1507. (b) Lee, J.K. and Kim, M.-J. (2002) Journal of Organic Chemistry, 67, 6845. (c) Kim, M.-J., Choi, M.Y., Lee, J.K. and Ahn, Y. (2003) Journal of Molecular Catalysis B: Enzymatic, 26, 115.

(d) Erbeldinger, M., Mesiano, A.J. and Russel, A. (2000) Biotechnology Progress, 16, 1129.

(e) Lau, R.M., Rantwijk, F., Seddon, K.R. and Sheldon, R.A. (2000) Organic Letters, 2, 4189.

(f) Itoh, T., Akasaki, E., Kudo, K. and Shirakami, S. (2001) Chemistry Letters, 262.

(g) Schoefer, S.H., Kraftzik, N., Wasserscheid, P. and Kragl, U. (2001) Chemical Communications, 425.

(h) Park, S. and Kazlauskas, R. (2001) Journal of Organic Chemistry, 66, 8395.

20 Kim, M.-J., Kim, D., Kim, H.M., Ahn, Y. and Park, J. (2004) Green Chemistry, 6, 471.
21 Masutani, K., Uchida, T., Irie, R. and Katsuki, T. (2000) Tetrahedron Letters, 41, 5119.

22 Dijksman, A., Elzinga, J.M., Li, Y.X., Arends, W.C.E. and Sheldon, R.A. (2002) Tetrahedron: Asymmetry, 13, 879.

23 van As, B.A.C., van Buijtenen, J., Heise, A., Broxterman, Q.B., Verzijl, G.K.M., Palmans, A.R.A. and Meijer, E.W. (2005) Journal of the American Chemical Society, 127, 9964.

24 Hilker, I., Rabani, G., Verzijl, G.K.M., Palmans, A.R.A. and Heise, A. (2006) Angewandte Chemie (International Edition in English), 45, 2130.

25 Choi, J.H., Kim, Y.H., Nam, S.H., Shin, S.T., Kim, M.-J. and Park, J. (2002) Angewandte Chemie (International Edition in English), 41, 2373.

26 Choi, J.H., Choi, Y.K., Kim, Y.H., Park, E.S., Kim, E.J., Kim, M.-J. and Park, J. (2004) Journal of Organic Chemistry, 69, 1972.

27 Kim, M.-J., Chung, Y.I., Choi, Y.K., Lee, H.K., Kim, D. and Park, J. (2003) Journal of the American Chemical Society, 125, 11494.

28 (a) Csjernyik, G., Bogár, K. and Bäckvall, J.-E. (2004) Tetrahedron Letters, 45 , 6799.

(b) Martin-Matute, B., Edin, M., Bogár, K. and Bäckvall, J.-E. (2004) Angewandte Chemie (International Edition in English), 43, 6535.

(c) Martin-Matute, B., Edin, M., Bogár, K., Kaynak, F.B. and Bäckvall, J.-E. (2005) Journal of the American Chemical Society, 127, 8817.

29 Borén, L., Martín-Matute, B., Xu, Y., Córdova, A. and Bäckvall, J.-E. (2006) Chemistry-A European Journal, 12, 225.

30 Kim, N., Ko, S.-B., Kwon, M.S., Kim, M.-J. and Park, J. (2005) Organic Letters, 7, 4523.

31 van Nispen, S.F.G., van Buijtenen, J., Vekemans, J.A.J., Meuldijk, J. and Hulshof, L.A. (2006) Tetrahedron: Asymmetry, 17, 2299.

32 Berkessel, A., Sebastian-Ibarz, M.L. and Müller, T.N. (2006) Angewandte Chemie (International Edition in English), 45, 6567.

33 Chabardes, P., Kuntz, E. and Varagnat, J. (1997) Tetrahedron, 33, 1775. 
34 Akai, S., Tanimoto, K., Kanao, Y., Egi, M., Yamamoto, T. and Kita, Y. (2006) Angewandte Chemie (International Edition in English), 45, 2592.

35 (a) Reetz, M.T. and Schimossek, K. (1996) Chimia, 50, 668.

(b) Choi, Y.K., Kim, M., Ahn, Y. and Kim, M.-J. (2001) Organic Letters, 3, 4099. (c) Pámies, O., Ell, A.H., Samec, J.S.M., Hermanns, N. and Bäckvall, J.-E. (2002) Tetrahedron Letters, 43, 4699. (d) Paetzold, J. and Bäckvall, J.-E. (2005) Journal of the American Chemical Society, 127, 17620.

(e) Parvulescu, A., Vos, D.D. and Jacobs, P. (2005) Chemical Communications, 5307. (f) Kim, M.-J., Kim, W.H., Han, K.-W., Choi, Y.K. and Park, J. (2007) Organic Letters, 9, 1157.

(g) Parvulescu, A., Jacobs, P. and Vos, D.D. (2007) Chemistry-A European Journal, 13, 2034. 
